Discussion Paper 131

Institute for Empirical Macroeconomics

Federal Reserve Bank of Minneapolis

90 Hennepin Avenue

Minneapolis, Minnesota 55480-0291

August 1999

\title{
Keynesian Conundrum: Multiplicity and Time Consistent Stabilization
}

\author{
Bill Dupor* \\ University of Pennsylvania
}

\begin{abstract}
This paper identifies a novel form of dynamic inconsistency of stabilization policy in increasing returns models that generate multiple equilibria. We present a two-period version of the Benhabib-Farmer (1994) externalities model and derive closed-form solutions for all endogenous variables in every perfect foresight equilibrium. We provide conditions under which the stabilization policy that maximizes time zero consumer welfare is not time consistent. Furthermore, we characterize the time consistent stabilization policy. Our results cast doubts on the usefulness of government coordination of economic activity when the government lacks a commitment mechanism. Without commitment, a benevolent government can rule out multiplicity only by ensuring that a pareto dominated equilibrium obtains.

*The author would like to thank Andrew Abel, Hal Cole, Russell Cooper, Joao Gomes, Robert Hall, Paul Klein, Narayana Kocherlakota, Ellen McGrattan, Jose-Victor Rios-Rull, Richard Rogerson, and Thomas Sargent for helpful comments, as well as seminar participants at the Federal Reserve Bank of Minneapolis, NBER Summer Institute, and Wharton. The views expressed herein are those of the author and not necessarily those of the Federal Reserve Bank of Minneapolis or the Federal Reserve System.
\end{abstract}




\title{
Keynesian Conundrum: Multiplicity and Time Consistent Stabilization
}

\author{
Bill Dupor*
}

\begin{abstract}
This paper identifies a novel form of dynamic inconsistency of stabilization policy in increasing returns models that generate multiple equilibria. We present a two-period version of the Benhabib-Farmer (1994) externalities model and derive closed-form solutions for all endogenous variables in every perfect foresight equilibrium. We provide conditions under which the stabilization policy that maximizes time zero consumer welfare is not time consistent. Furthermore, we characterize the time consistent stabilization policy. Our results cast doubts on the usefulness of government coordination of economic activity when the government lacks a commitment mechanism. Without commitment, a benevolent government can rule out multiplicity only by ensuring that a pareto dominated equilibrium obtains.
\end{abstract}

Models that display multiple, self-fulfilling rational expectations equilibria provide an interesting mechanism for understanding business cycles. Recent work on multiple, self-fulfilling rational expectations equilibria includes Azari-

*Assistant Professor of Finance, The Wharton School, University of Pennsylvania.

Address: 2322 Steinberg Hall-Dietrich Hall, Philadelphia PA 19104-6367, (215) 898-7634, (215) 898-6200 FAX, dupor@wharton.upenn.edu. The author would like to thank Andrew Abel, Hal Cole, Russell Cooper, Joao Gomes, Robert Hall, Paul Klein, Narayana Kocherlakota, Ellen McGrattan, Jose-Victor Rios-Rull, Richard Rogerson and Thomas Sargent for helpful comments, as well as seminar participants at the Federal Reserve Bank of Minneapolis, NBER Summer Institute and Wharton. This version: July 26, 1999. 
adis (1981), Farmer and Woodford (1984), Howitt and McAfee (1992), Kiyotaki (1988), Shleifer (1986), Weil (1989) and Woodford (1988). These models do not require large shocks to consumer preferences or technology, as in real business cycle models, or large exogenous random policy errors, as in monetary models, in order to generate economic fluctuations. In addition, multiplicity may provide a role for government intervention. As Benhabib and Farmer (1994, p. 40) point out, "it may be important to explore the possibility that some classes of policy interventions may be associated with higher economic welfare." In a similar vein, Woodford (1991, p. 79) states "it remains possible to distinguish policy regimes or institutional arrangements that allow for sunspot equilibria from those that do not, and the choice of policies or institutions of the latter sort to rule out one possible source of aggregate instability may itself be an appropriate object of public policy."

In this paper, we consider a government that cannot levy taxes, but instead can coordinate expectations of households in the economy. The government 'selects' from the set of equilibria to maximize consumer welfare. One may think of this policy as a signal that households use to coordinate expectations. The idea of government policy coordinating equilibria without affecting prices or budget sets of households is not new to us. ${ }^{1}$ If a benevolent government has access to tools that allow it to pick one of the multiple equilibria, it will pick the equilibrium that involves the highest consumer welfare. We show that in a two-period version of the Benhabib-Farmer model, a policy that picks the equilibrium with the highest time zero consumer welfare may not be time consistent. In addition, we show that our results apply if the government selects a labor income tax instead

\footnotetext{
${ }^{1}$ Evans, Honkapohja, Romer (1999, p. 508) study a model where "when firms make investment decisions, they pay careful attention to expectations about future economic activity and understand that the expectations of other firms will determine what takes place. Announcements about monetary policy are one example of a variable that could coordinate the expectations that different firms form." In a growth model with mutliple equilibria, Matsuyama (1991) describes the role for government in promoting confidence and optimism in the private sector.
} 
of coordinating household expectations.

In the Benhabib-Farmer model, external returns to labor generates increasing social returns to labor. If external effects are sufficiently strong, there is an upward sloping labor demand curve. This can lead to multiple equilibria due to self-fulfilling rational expectations. In addition, external returns to capital lead to an undersupply of capital in equilibrium. Government manipulation of household expectations in the future affects savings and labor supply decisions in the present.

In addition to generating multiplicity, increasing returns has implications for optimal resource allocations. Importantly, increasing returns can imply that an optimal allocation involves production bunching. Production bunching and the undersupply of savings are essential in explaining the time consistency problem in stabilization policy. Let us sketch out the model and the intuition for the main result.

Our model has two periods. There is a labor supply decision in both periods and a capital accumulation decision between periods. The optimal government policy under commitment takes the following form. The government selects an equilibrium with high initial period labor supply and low final period labor supply. The government chooses an equilibrium with high labor supply in the initial period because labor externalities lead to an undersupply of labor in equilibrium. Why does the government announce that equilibrium labor supply will be low in the final period? If households believe that labor supply will be low in the final period, in the model they respond by increasing labor supply and savings in the initial period. ${ }^{2}$ With labor and capital externalities, this brings the initial period variables closer to the pareto optimal level. Households still enjoy high consumption in the final period through accumulated capital. Production is bunched in the initial period.

\footnotetext{
${ }^{2}$ The result that initial period labor supply and savings increases in response to a decrease in future labor supply depends upon the particular stance take on preferences and technology, as we explain below.
} 
Now imagine the government enters the final period and is allowed to reoptimize. With increasing returns, it would like to select an equilibrium with high final period labor supply in order to take advantage of the convex production technology. In addition, the benefits of high initial period savings and labor input cannot be reversed; therefore, the benevolent government has no incentive to stick to the previously announced low final period labor supply. Forward looking households realize that a government acting sequentially cannot credibly commit to a policy intervention that is welfare-maximizing among the entire class of policy interventions.

In the next section, we present a two-period competitive model with external returns and characterize the perfect foresight equilibria. In section 2, we characterize the optimal stabilization policy with and without commitment and reinterpret our stabilization policy as a certain state-contingent tax policy. Section 3 discusses several aspects and implications of our results. Section 4 concludes.

\section{Two-Period Benhabib-Farmer Model}

In this section, we present a two-period equilibrium model with increasing returns, production externalities and capital accumulation. We provide closed-form solutions for the entire set of perfect foresight equilibria.

\section{Household Problem}

The economy consists of a large number of identical households who live for two periods. Households derive utility from consumption and not working according to

$$
\sum_{t=0}^{1}\left[u\left(c_{t}\right)-v\left(n_{t}\right)\right]
$$

where $c_{t}$ and $n_{t}$ denote period $t$ consumption and labor supply. Each household is endowed with an initial quantity of capital $k_{0}$ and a share in the representative firm of the economy. Each share pays profit $\pi_{t}$ in period $t$.

In addition to choosing consumption and leisure, agents may also hold capital $k_{1}$, between periods zero and one. Each household maximizes (1) by choice of 
$\left\{c_{0}, c_{1}, k_{1}, n_{0}, n_{1}\right\}$ subject to:

$$
k_{t+1}=r_{t} k_{t}+\delta k_{t}+w_{t} n_{t}+\pi_{t}-c_{t}
$$

for $t=0,1$, where $k_{0}=1, k_{2}=0$. Given our finite horizon, there is no incentive to hold capital past period 1. Finally, households have rational expectations regarding and take as given $w_{t}$ and $r_{t}$, the period $t$ wage and real interest rate.

Optimization by households at an interior requires

$$
\frac{v^{\prime}\left(n_{t}\right)}{u^{\prime}\left(c_{t}\right)}=w_{t}
$$

for $t=0,1$,

$$
\frac{u^{\prime}\left(c_{0}\right)}{u^{\prime}\left(c_{1}\right)}=r_{1}+\delta
$$

and that the budget constraint (2) is satisfied with equality for $t=0,1$.

This completes our description of the household problem and the associated necessary conditions for optimization. Next, consider the firm's problem.

\section{Firm Problem}

The aggregate production function is

$$
y_{t}=\left(k_{t}\right)^{\alpha}\left(n_{t}\right)^{\beta}
$$

where $\alpha, \beta>0$ and $\alpha+\beta>1$. This production technology exhibits increasing returns-to-scale. The aggregate production function is different from that faced by individual firms.

The economy consists of a large number of identical firms, each of which produces output according a production function with externalities. We assume that if average economy-wide level of labor is positive, the firm-level production function is

$$
y_{t}=\left(k_{t}\right)^{a}\left(n_{t}\right)^{b}\left(\bar{k}_{t}\right)^{\alpha-a}\left(\bar{n}_{t}\right)^{\beta-b}
$$

where $\bar{k}_{t}$ and $\bar{n}_{t}$ represent the average economy-wide levels of capital and labor. If $\bar{n}_{t}=0$, firm-level production is given by $y_{t}=\left(k_{t}\right)^{\alpha}\left(n_{t}\right)^{\beta}$. This technical assumption rules out zero labor supply equilibria. Since there are a large number 
of firms, from the perspective of a single firm, these external effects are exogenous. We study symmetric equilibria where $k_{t}=\bar{k}_{t}$ and $n_{t}=\bar{n}_{t}$. Finally, each firm privately faces constant returns-to-scale, $a+b=1$, and $a, b>0$.

In each period, a firm chooses capital and labor to maximize profits, given by

$$
\pi_{t}=y_{t}-r_{t} k_{t}-w_{t} n_{t}
$$

taking $r_{t}$ and $w_{t}$ as given. Profit maximization implies

$$
\begin{aligned}
& r_{t} k_{t}=a y_{t} \\
& w_{t} n_{t}=b y_{t}
\end{aligned}
$$

for $t=0,1$. This completes our description of the firm problem and the associated necessary conditions for profit maximization.

\section{Equilibrium}

We summarize the necessary conditions that the endogenous variables $\left\{n_{0}, n_{1}, c_{0}, c_{1}, k_{1}\right\}$ must satisfy in any perfect foresight equilibrium (PFE) by substituting out factor prices using (5) and (6). These conditions are

$$
\begin{gathered}
v^{\prime}\left(n_{t}\right)=b u^{\prime}\left(c_{t}\right)\left(k_{t}\right)^{\alpha}\left(n_{t}\right)^{\beta-1} \text { for } t=0,1 \\
u^{\prime}\left(c_{0}\right)=u^{\prime}\left(c_{1}\right)\left(a\left(k_{1}\right)^{\alpha-1}\left(n_{1}\right)^{\beta}+\delta\right)
\end{gathered}
$$

as well as the resource constraint

$$
k_{t+1}=\left(k_{t}\right)^{\alpha}\left(n_{t}\right)^{\beta}+\delta k_{t}-c_{t} \text { for } t=0,1
$$

where $k_{0}=1$ and $k_{2}=0$.

Next, we make functional form assumptions in order to construct closed-form expressions for the entire set of PFE. Let us assume $\alpha=1, \beta=2, u(c)=\log (c)$ and $v(n)=n$. In this case, our necessary conditions become

$$
\begin{aligned}
& c_{t}=b k_{t} n_{t} \text { for } t=0,1 \\
& c_{1}=c_{0}\left(a\left(n_{1}\right)^{2}+\delta\right)
\end{aligned}
$$




$$
\begin{gathered}
c_{1}=k_{1}\left(n_{1}\right)^{2}+\delta k_{1} \\
c_{0}+k_{1}=k_{0}\left(n_{0}\right)^{2}+\delta k_{0}
\end{gathered}
$$

We will shortly study the optimal policy when the government is able to select among equilibrium resource allocations. The government will maximize (1) subject to the resource constraints (12) and (13), as well as the constraint that the labor supply choice is consistent with an equilibrium in both periods (10), and that the capital allocation is consistent with an equilibrium (11). This Ramsey problem is non-standard only in that the government does not select from a set of tax instruments, but from among a set of equilibria.

Of course, the government choice of equilibria is trivial if the equilibrium is unique. It is therefore important to establish that there is not necessarily a unique PFE. Substituting out $c_{1}$ in (12) using (10) at $t=1$, we have

$$
k_{1}\left(n_{1}\right)^{2}-b k_{1} n_{1}+\delta k_{1}=0
$$

Since $k_{1}$ must be positive if consumption is positive at $t=1$, we may cancel $k_{1}$. We are left with a quadratic equation in $n_{1}$.

$$
\left(n_{1}\right)^{2}-b n_{1}+\delta=0
$$

Applying the quadratic formula to (14), there are two possible values of labor supply at $t=1$ :

$$
\begin{aligned}
& n_{1}^{h}=\frac{1}{2}\left(b+\sqrt{b^{2}-4 \delta}\right) \\
& n_{1}^{l}=\frac{1}{2}\left(b-\sqrt{b^{2}-4 \delta}\right)
\end{aligned}
$$

In order for $n_{1}^{h}, n_{1}^{l}$ to be real valued, we assume that $b^{2}>4 \delta .{ }^{3}$ Note that $n_{1}$ does not depend on $k_{1}$. A larger capital $k_{1}$ induces a positive income effect in the

\footnotetext{
${ }^{3}$ Given that $b<1$, it may seem that the retention rate $\delta$ would have to be unrealistically low in order to generate multiple equilibrium. Two comments are in order. First, the retention rate in our two period model is difficult to compare with the same parameter in an infinite horizon model. Second, our analysis sets out to describe a new mechanism for time inconsistency of government policy. Several unrealistic assumptions, such as the aggregate production function (3) and a low retention rate, are adopted in order to derive closed form solutions and analytic results.
} 
final period, because undepreciated capital is consumed, which tends to reduce $n_{1}$. On the other hand, a larger capital stock raises the marginal product of labor, which tends to increase $n_{1}$. These two effects exactly cancel out with log utility in consumption and constant social returns to capital. This is important because the government choice of labor supply entering into the final period will be independent of initial period actions of the government or households.

At $t=1$, labor supply will either be high or low and less than $b$, which we state as a lemma.

Lemma 1: $0<n_{1}^{l}<b / 2<n_{1}^{h}<b<1$.

Proof of Lemma 1: All proofs are in the appendix.

Lemma 1 will be useful in characterizing the initial period labor supply. In particular, if households expect that $w_{1}$ will be low because aggregate labor supply is low at time one, then they will increase time zero labor supply because of a wealth effect. Since the production of output is convex in labor, total output across the two periods may be largest if labor supply is bunched in the initial period.

Next, we characterize labor supply at $t=0$. Substituting (10) and (13) into (11) gives us a quadratic equation in $n_{0}$.

$$
n_{1}\left(n_{0}\right)^{2}-\left[b n_{1}+\delta+a\left(n_{1}\right)^{2}\right] n_{0}+\delta n_{1}=0
$$

For a given value of $n_{1}$, two distinct values for $n_{0}$ solve this quadratic equation. Since there are two potential values for $n_{1}$, there are a total of four possible values of labor supply at $t=0$, which we denote $n_{0}^{i j}$ for $i=h, l$ and $j=h, l$. Letting $\theta^{j}=b n_{1}^{j}+\delta+a\left(n_{1}^{j}\right)^{2}$, the four equilibrium period zero values of labor supply are

$$
\begin{aligned}
& n_{0}^{h j}=\frac{1}{2 n_{1}^{j}}\left(\theta^{j}+\sqrt{\left(\theta^{j}\right)^{2}-4 \delta\left(n_{1}^{j}\right)^{2}}\right) \\
& n_{0}^{l j}=\frac{1}{2 n_{1}^{j}}\left(\theta^{j}-\sqrt{\left(\theta^{j}\right)^{2}-4 \delta\left(n_{1}^{j}\right)^{2}}\right)
\end{aligned}
$$


for $j=h, l$. Summarizing, there are four equilibria, each of which is described by a pair $\left(n_{0}^{i j}, n_{1}^{j}\right)$ for $i=h, l$ and $j=h, l .^{4}$

It is a straightforward to show that $n_{0}^{h l}>n_{0}^{h h}$ by examining (17) and (18). This provides a partial explanation of why the production bunching equilibrium maximizes time zero household welfare. Expectation of $n_{1}^{l}$ instead of $n_{1}^{h}$ leads to greater labor supply in the initial period. The intuition for this inequality is not straightforward. Recall that by equation (14), final period labor supply does not depend on $k_{1}$. This occurred because there were offsetting income and substitution effects on final period labor supply.

One might expect that these offsetting income and substitution effects would imply that $n_{0}$ and $k_{1}$ do not depend on $n_{1}$. Why is this not the case? First, announcing that labor supply will be lower in the future period reduces income in the future period. This income effect tends to increase $n_{0}$ and $k_{1}$. This effect was emphasized in the introduction. On the other hand, announcing a low future labor supply also reduces the real interest rate since the future marginal product of capital will be lower if future labor supply is low. This effect tends to reduce $n_{0}$ and $k_{1}$. However, this effect is smaller in magnitude than the opposing income effect because there are capital externalities. Equation (11) demonstrates that only part of the returns to capital, in the form of higher labor productivity, are internalized; therefore, only part of this real interest rate effect is internal to the firm. For example, without external returns to capital in this model, $n_{0}$ would not depend on $n_{1}$.

The remaining endogenous variables for a particular equilibrium may be calculated using the above necessary conditions. The law of motion for consumption is

$$
\begin{gathered}
c_{0}^{i j}=b n_{0}^{i j} \\
c_{1}^{i j}=b n_{1}^{j}\left[\left(n_{0}^{i j}\right)^{2}-b n_{0}^{i j}+\delta\right]
\end{gathered}
$$

\footnotetext{
${ }^{4}$ Time zero labor is positive in every equilibrium by straightforward examination of (17) and
} (18). 
This completes our characterization of the model's perfect foresight equilibria. In the next section, we present the optimal stabilization policy with and without commitment. We will make repeated use of our expressions for the equilibrium values of consumption and labor derived above.

\section{Optimal Stabilization Policy}

In the previous section, we provided conditions under which there exists multiple equilibria due to increasing returns. As discussed in the introduction, equilibrium multiplicity may provide a justification for government intervention. We study the policy of a benevolent government that selects from among the set of perfect foresight equilibria with and without commitment. The timing of decisions in both cases is presented in Diagram 1.

\section{$2.1 \quad$ Without Commitment}

Without commitment, we solve the government's problem by working backwards. First, consider the optimal government policy in the final period.

\section{Final Period}

Entering period one, $k_{1}$ is given by previous actions of households, firms and the government. Taking $k_{1}$ as given, the government chooses a value of $n_{1}$ to maximize consumer welfare at $t=1$ that is consistent with equilibrium. Let $z_{1}$ denote the utility of the representative household entering the final period with capital $k_{1}$, where the government behaves optimally:

$$
z_{1}\left(k_{1}\right)=\max _{n_{1} \in\left\{n_{1}^{h}, n_{1}^{l}\right\}}\left\{\log \left(c_{1}\right)-n_{1}\right\}
$$

where $c_{1}=b k_{1} n_{1}$. This restriction for $c_{1}$ is the incentive compatibility constraint (10) at $t=1$.

If $n_{1}$ were a continuous choice variable, the value function would be maximized at labor equal to one. Note that this is independent of the value of $k_{1}$ for reasons described in section 1 . In addition, the objective is concave and increasing in $n_{1}$ for $n_{1} \leq 1$. Since both choices for labor $\left\{n_{1}^{h}, n_{1}^{l}\right\}$ are less than one by 
lemma 1, the optimizing government will choose the larger value $n_{1}^{h}$.

The intuition for this result is straightforward. Since there are positive external returns to labor, part of productive labor effort is not internalized to the firm. At time one, every equilibrium value of labor supply is, therefore, less than the pareto optimal choice of $n_{1}$. From among the equilibrium values of labor, $n_{1}^{h}$ and $n_{1}^{l}$, a higher labor supply is preferred. Having chosen the optimal final period policy, consider the optimal initial period policy.

\section{Initial Period}

At time zero, the government chooses labor supply $n_{0}$ to maximize

$$
z_{0}=\max _{n_{0} \in\left\{n_{0}^{h h}, n_{0}^{l h}\right\}} \log \left(c_{0}\right)+\log \left(c_{1}\right)-n_{0}-n_{1}^{h}
$$

subject to (19) and (20), which define the law of motion for consumption. The time zero government takes the optimal labor supply decision in the final period as given at $n_{1}^{h}$. Substituting (19) and (20) into (22), we have

$$
z_{0}=\max _{n_{0} \in\left\{n_{0}^{h h}, n_{0}^{l h}\right\}} \log \left(b n_{0}\right)+\log \left(b n_{1}^{h}\left[\left(n_{0}\right)^{2}-b n_{0}+\delta\right]\right)-n_{0}-n_{1}^{h}
$$

Next, we must find the optimal $n_{0}$. The next three lemmas will be useful.

Lemma 2: For $n_{0} \in[b, 2 b), U\left(n_{0}, n_{1}\right)$ is increasing $n_{0}$.

The intuition for Lemma 2 is straightforward. Since there is an undersupply of labor due to positive labor externalities in both periods, every equilibrium involves too little labor supply relative to the pareto optimal allocation. The only caveat to this statement is that for very low levels of $n_{0}, U$ may be decreasing in $n_{0}$. When $n_{0}$ is very low, the marginal product of labor is low and the marginal disutilty of working is one. This does not occur in the relevant region $n_{0} \in[b, 2 b)$. The next lemma provides three inequalities concerning initial period labor supply in the alternative equilibria.

Lemma 3: (i) $n_{0}^{l h}<b / 2$; (ii) $n_{0}^{h h}>b$; (iii) $n_{0}^{h h}<2 b$. 
Lemma 4: $U\left(b, n_{1}\right)>U\left(n_{0}, n_{1}\right)$ if $0<n_{0}<b$.

Theorem 1: The time consistent optimal government stabilization policy is $\left(n_{0}^{h h}, n_{1}^{h}\right)$.

It was previously established that at time one, a government that maximizes household welfare chooses the equilibria with high labor supply. At time zero, the government must choose labor supply that is consistent with both equilibrium as well as high time one labor supply. The government may select either $n_{0}^{l h}$ or $n_{0}^{h h}$. Together Lemmas 2 and 4 show that in a relevant range, higher labor supply is preferred to lower labor supply. This occurs because positive labor externalities lead to an undersupply of labor in every equilibrium. Finally, Lemma 3 demonstrates that $n_{0}^{l h}$ is less than $n_{0}^{h h}$ and that both $n_{0}^{l h}$ and $n_{0}^{h h}$ are in the relevant range of labor supply values. Therefore, the welfare-maximizing time consistent equilibrium involves high labor supply in both periods.

In the next section, we show that under commitment the time zero welfaremaximizing equilibrium involves high initial and low future labor supply.

\subsection{Under Commitment}

First, consider the problem of a benevolent government under commitment. With commitment, the government selects $\left(n_{0}, n_{1}\right)$ from the entire set of PFE in order to maximize

$$
\log \left(c_{0}\right)+\log \left(c_{1}\right)-n_{0}-n_{1}
$$

subject to (19), (20) and the restriction $\left(n_{0}, n_{1}\right) \in\left\{\left(n_{0}^{i j}, n_{1}^{j}\right)\right\}_{i=h, l ; j=h, l}$. Substituting out (19) and (20), the government objective function is

$$
U\left(n_{0}, n_{1}\right)=\log \left(b n_{0}\right)+\log \left(b n_{1}\right)+\log \left(\left(n_{0}\right)^{2}-b n_{0}+\delta\right)-n_{0}-n_{1}
$$

Note that $U_{12}=0$.

Lemma 5: (i) $n_{0}^{l l}<n_{0}^{h l}$; (ii) $n_{0}^{l h}<n_{0}^{h h}$; (iii) $n_{0}^{h l}>b$; (iv) $n_{0}^{h l}<2 b$.

The following theorem provides conditions under which a benevolent government under commitment would choose the production bunching equilibrium. 
The main expression in Theorem 2 that must be checked is (23), which determines whether higher utility is achieved under $\left(n_{0}^{h l}, n_{1}^{l}\right)$ than $\left(n_{0}^{h h}, n_{1}^{h}\right)$. This expression is complicated.

Theorem 2: The time zero optimal government stabilization policy under commitment is $\left(n_{0}^{h l}, n_{1}^{l}\right)$ if and only if

$$
\frac{k_{1}^{h l} \phi^{l}}{k_{1}^{h h} \phi^{h}}>\exp \left(b \sqrt{b^{2}-4 \delta}-b^{2}+4 \delta\right)^{1 / 2}\left\{\exp \left[b^{2}(4-b) \sqrt{b^{2}-4 \delta}\right]\right\}^{1 / 4}
$$

where $\phi^{j}=\theta^{j}+\sqrt{\left(\theta^{j}\right)^{2}-4 \delta\left(n_{1}^{j}\right)^{2}}$.

The proof of theorem 2 consists of three pairwise time zero utility comparisons of different equilibria. Let $U_{0}^{i j}$ denote the time zero household utility of equilibrium $\left(n_{0}^{i j}, n_{1}^{j}\right)$. First, we show that $U_{0}^{h h}>U_{0}^{l h}$. Lemmas 2 and 4 provided conditions under which higher $n_{0}$ holding fixed $n_{1}$ results in higher household utility. These results apply since, by Lemma 5 (ii), $n_{0}^{h h}>n_{0}^{l h}$. Second, as a part of the proof of Theorem 1, we establish $U_{0}^{h l}>U_{0}^{l l}$. Recall that there are returns to labor that are not internalized to the firm. In every equilibrium, there is an undersupply of labor. Intuitively, an equilibrium with low labor supply in both periods is pareto dominated by an equilibrium with high labor supply in at least one period.

The third and final required inequality is $U_{0}^{h l}>U_{0}^{h h}$. This inequality holds if and only if (23) is true. Because of external returns to labor, there is too little labor and output in every equilibrium. At first look, it may seem that the equilibrium that $\left(n_{0}^{h h}, n_{1}^{h}\right)$ generates the greatest total output. This is not necessarily true. Imagine a household at time zero has a change in expectations that wages at time one will be low instead of high. The reduction in permanent income induces the household to increase time zero labor supply. In fact, it is possible to show that $n_{0}^{h l}>n_{0}^{h h}$. Because of increasing returns to labor, a higher $n_{0}$ increases the marginal product of labor and therefore the wage. Thus, the income effect of a falling future wage is amplified by the substitution effect. 
Not every parameter configuration generates a time consistency problem. In Section 3, we compute numerically which values of the underlying parameters $(b, \delta)$ imply $U_{0}^{h l}>U_{0}^{h h}$. If $U_{0}^{h l}<U_{0}^{h h}$ or, equivalently, (23) holds, then the highest time zero utility equilibrium is $\left(n_{0}^{h h}, n_{1}^{h}\right)$ and there is no time consistency problem.

In part, theorem 2 holds because a benevolent stabilization authority recognizes the usefulness of production bunching when there is increasing returns to labor. It may not be obvious why high labor is preferred in the initial period over high labor in the final period. Why is $U_{0}^{h l} \neq U_{0}^{l h}$ ? When labor is high in the initial period, the capital stock is high between the initial and final periods. This has two effects. First, it allows the household to save output across periods. Second, a high capital stock in the final period raises the productivity of labor in the final period. This second channel is not operative if production is bunched in the final period; therefore, the welfare maximizing equilibrium concentrates production in the initial period instead of the final period.

Let us take a sample parameter configuration. Consider the following selection of underlying parameter values: $b=0.7, \delta=0.1$. In this case, the assumptions of theorem 1 clearly hold and the time consistent strategy involves high labor supply in both periods. In addition, the assumptions of theorem 2 hold and the optimal policy with commitment is $\left(n_{0}^{h l}, n_{1}^{l}\right)$. Table 1 lists the endogenous variables and time zero household utility in every equilibrium. Labor supply in the high-high equilibrium is $\left(n_{0}^{h h}, n_{1}^{h}\right)=(0.94,0.50)$, with time zero utility $U_{0}^{h h}=-4.11$. Labor supply in the high-low equilibrium is $\left(n_{0}^{h l}, n_{1}^{l}\right)=(1.17,0.20)$, with time zero utility $U_{0}^{h l}=-3.96$.

The highest utility equilibrium involves high initial labor supply and low future labor supply. This is consistent with production bunching-higher labor supply increases the marginal product of labor because of increasing returns. It should not be surprising that this equilibrium gives the highest utility. As explained in Theorem 1, this equilibrium is not time consistent because the time one government, if given the opportunity to deviate, will choose high labor supply 
in order to take advantage of increasing returns.

It is important not to focus on total labor supply across both periods as a measure of economic activity. Note that total labor effort is greater in the

high-high equilibrium, that is $n_{0}^{h h}+n_{1}^{h}>n_{0}^{h l}+n_{1}^{l}$. This does not contradict theorem 2, because households are really concerned about is total output (with some emphasis on its time profile). If the production function is convex in labor, then an unevenly distributed labor supply with a lower total may generate more output than an evenly distributed labor supply with a higher total. In addition, the capital stock is much larger in the production bunching equilibrium, which is welfare improving because of the external effects of capital.

\subsection{Stabilization Policy as a State-Contingent Tax Policy}

In a two-period growth model with external returns to capital and labor, a policy that coordinates the expectations of households to maximize consumer welfare may not be time consistent. Despite several examples of models where this kind of stabilization policy is discussed, notably Evans et al (1998) and Matsuyama (1991), the reader may question the realism or workability of this kind of stabilization policy. Instead, several authors have studied tax policies that rule out multiplicity in equilibrium models, such as Christiano and Harrison (1999) and Guo and Lansing (1998). In this section, we describe how our stabilization policy can be reinterpreted as a certain type of state contingent labor tax policy.

Assume the government selects a tax on labor $\tau_{t}=\tau_{t}\left(n_{t}\right)$ for $t=0,1$ as a function of individual labor supply. In addition, assume that the government cannot borrow or lend, may only issue lump-sum rebates and cannot collect lump-sum taxes. These assumptions together imply $\tau_{t} \geq 0$ in order that the government budget constraint is satisfied. Let the government choose a set of functions $\left(\tau_{0}, \tau_{1}\right)$ to maximize household welfare subject to the constraint that the equilibrium implied by the choice of $\tau_{t}\left(n_{t}\right)$ for $t=0,1$ is unique.

First, consider the time consistent solution to this problem. Entering the final period, the government would not impose a tax on labor supply in equilibrium 
since every equilibrium $n_{1}$ involves too little labor supply in the final period. ${ }^{5}$ Although the government will not tax labor in equilibrium, it would prefer $n_{1}^{h}$ obtain. It can accomplish this by setting $\tau_{1}\left(n_{1}^{l}\right)$ very high. This makes the low labor supply inconsistent with consumer optimization and, therefore, equilibrium. Without commitment, the tax policy guarantees final period labor equals $n_{1}^{h}$.

Working backwards, the initial period government maximizes time zero utility subject to the constraint that equilibrium taxes will be zero at $t=1$ and that $n_{1}=n_{1}^{h}$. By the same argument as above, the government will not tax initial period labor in equilibrium and it prefers $n_{0}^{h h}$ to $n_{0}^{l h}$. It can accomplish this by setting $\tau_{0}\left(n_{0}^{l h}\right)$ very high and $\tau_{0}\left(n_{0}^{h h}\right)=0$. Therefore, the time consistent allocation where the government coordinates households expectations is identical to the time consistent allocation where the government selects a state-contingent tax policy.

Next, consider the solution to the government problem with commitment. The allocation $\left(n_{0}^{h l}, n_{1}^{l}\right)$ is feasible under this policy. This equilibrium obtains if the government sets $\tau_{0}\left(n_{0}^{h l}\right)=\tau_{1}\left(n_{1}^{l}\right)=0$ and $\tau_{t}$ very high at all other values of labor supply. This demonstrates that there is a time consistency problem when government chooses a tax policy. There exists a feasible allocation with commitment $\left(n_{0}^{h l}, n_{1}^{l}\right)$ which dominates the optimal allocation without commitment $\left(n_{0}^{h h}, n_{1}^{h}\right)$.

In fact, although $\left(n_{0}^{h l}, n_{1}^{l}\right)$ is feasible under commitment, it may not be optimal. Under commitment, the government may want to have a positive final period labor tax in equilibrium since a value of $n_{1}$ below $n_{1}^{l}$ may induce greater initial period savings and labor input that increases welfare. This implies that using tax policy instead of equilibrium selection as the policy instrument may magnify the time consistency problem by increasing welfare under commitment

\footnotetext{
${ }^{5}$ The government would like to subsidize labor in equilibrium because of the externality. This is ruled out by our asssumptions that the goverment may not borrow or issue lump sum taxes.
} 
and leaving welfare unchanged without commitment.

\section{$3 \quad$ Further Exploration}

Using a discrete time, finite horizon model, we have analytically characterized the endogenous variables in every PFE of the model. Since there are only two free parameters of the model, the depreciation rate $(1-\delta)$ and the private returns to labor $b$, it is easy to trace out all of the parameter configurations that generate time inconsistency.

Figure 3 identifies the highest time zero utility equilibrium for all configurations of $b$ and $\delta$. Values of $\delta$ are on the vertical axis and values of $b$ are on the horizontal axis. An ' $\mathrm{x}$ ' denotes a $(b, \delta)$ pair with highest utility occurring at $\left(n_{0}^{h l}, n_{1}^{l}\right)$ and an 'o' denotes a $(b, \delta)$ pair with highest utility occurring at $\left(n_{0}^{h h}, n_{1}^{h}\right)$. The upper left side of the graph is blank. In this range, $b^{2}<4 \delta$ and there are no equilibria where households are at an interior solution. Also, there is no region where the other two equilibria, both of which involve low time zero labor supply, maximize time zero welfare. Over the entire region, Theorem 1 demonstrates that the time consistent welfare-maximizing equilibrium is $\left(n_{0}^{h h}, n_{1}^{h}\right)$.

From Figure 3, we see that the region where $\left(n_{0}^{h h}, n_{1}^{h}\right)$ maximizes time zero utility under commitment involves by low values of $b$ and $\delta$. First, consider the private returns to labor, $b$. A low value of $b$ implies that equilibrium labor supply is low. If labor supply is sufficiently close to zero, then the marginal product of labor becomes close to linear. If production is close to linear in labor, then the incentives for production bunching are diminished. For sufficiently small $b$, if multiple equilibria exist, then the highest welfare equilibrium is $\left(n_{0}^{h h}, n_{1}^{h}\right)$.

Second, consider the capital depreciation rate $(1-\delta)$. One feature of the Benhabib-Farmer model in discrete time is that if capital depreciates fully after one period, then the model will not exhibit multiple equilibria. High depreciation removes the time consistency problem, because if $\delta$ is close to zero then the time zero welfare maximizing equilibrium with and without commitment is $\left(n_{0}^{h h}, n_{1}^{h}\right)$. 
High depreciation reduces the ability of capital to smooth consumption between periods zero and one. This makes the production bunching of the $\left(n_{0}^{h l}, n_{1}^{l}\right)$ equilibrium less attractive to a benevolent government. In the extreme case where $\delta=0$, it is straightforward to show that the equilibrium is unique and $n_{0}=b+(1-b) b, n_{1}=b$.

An advantage of using a two period model with restrictive assumptions governing production and preference parameters is that we are able to prove results regarding the time consistency of optimal stabilization policy. In some respects the model is not standard. For example, Benhabib and Farmer (1993) and Guo and Lansing (1998) consider an infinite horizon, continuous time model. Christiano and Harrison (1996) study a discrete time infinite horizon model. In numerical simulations not reported in this paper, we demonstrate that this type of time consistency problem arises in this Benhabib-Farmer model if time is continuous and the horizon is infinite.

\section{Conclusion}

In this paper, we have identified a new form of time inconsistency in a standard model of endogenous fluctuations. In a dynamic growth model with external returns to capital and labor, a stabilization policy that selects the equilibrium with highest time zero utility may not be time consistent. That is, if the government is able to revisit its stabilization plan at a future date, it may wish to change its plan. Our expectation coordination policy was reinterpreted as a tax policy. In this case, the time consistency problem remains and may be amplified.

Our result is important because it casts doubt on the usefulness of stabilization policy to remove fluctuations in a class of 'animal spirit' models. In this model, it is possible for the government to stabilize the economy by selecting an equilibrium; however, without a commitment mechanism, the stabilization policy guarantees that the highest time-zero utility equilibrium cannot be reached and a pareto inferior equilibrium is chosen instead.

This potentially leaves the government with a difficult conundrum: if it 
chooses to stabilize the economy by selecting an equilibrium, it will ensure that a pareto inferior equilibrium occurs with probability one. If the government is able to "walk away" from conducting a stabilization policy, then there may be some chance that households and firms will have expectations that imply the highest time-zero utility equilibrium obtains. Stated another way, imagine that the government believes that households have sufficiently optimistic expectations so that there is a strong chance a high utility equilibrium obtains in absence of government intervention. In this case, the government may prefer to conduct no stabilization policy if it can feasibly do so. 


\section{Appendix: Proofs of Theorems and Lemmas}

Proof of Lemma 1: This holds by (14), and because $\delta>0$.

Proof of Lemma 2: Now we would like to represent some features of household utility as a function of $n_{0}$. Since utility is separable from $n_{1}$, it is sufficient to study

$$
\hat{U}\left(n_{0}\right)=\log \left(n_{0}\right)+\log \left(n_{0}^{2}-b n_{0}+\delta\right)-n_{0}
$$

We know that $n_{0}$ can only take on one of four values; however, it will be important to develop some facts about the function $\hat{U}$. Because utility is unaffected up to a monotone transformation, we may equivalently study $V\left(n_{0}\right)=\exp \left(\hat{U}\left(n_{0}\right)\right)$. Note that

$$
V\left(n_{0}\right)=\left(n_{0}^{2}-b n_{0}+\delta\right)\left[n_{0} \exp \left(-n_{0}\right)\right]
$$

Taking the first derivative:

$$
V^{\prime}\left(n_{0}\right)=\exp \left(-n_{0}\right)\left[-n_{0}^{3}+(b+3) n_{0}^{2}-(2 b+\delta) n_{0}+\delta\right]
$$

Letting $f\left(n_{0}\right)=-n_{0}^{3}+(b+3) n_{0}^{2}-(2 b+\delta) n_{0}+\delta$, it is clear that $f\left(n_{0}\right)>0$ implies $V^{\prime}\left(n_{0}\right)>0$.

Note that $f$ is a cubic equation with a negative sign on the $\left(n_{0}\right)^{3}$ term. This implies $f$ has only one region where $f$ is increasing. See Figure 1. Evaluating the function and its first derivative at $n_{0}=b$, we have $f(b)=b^{2}+\delta(1-b)>0$ and $f^{\prime}(b)=b(4-b)-\delta>0$. Therefore, $f$ is positive at $n_{0}=b$ and it belongs to the increasing region of $f$. For any $x>b$, if $f^{\prime}(x)>0$ it must be the case that $f\left(n_{0}\right)>0$ for all $n_{0} \in(b, x)$. Simple algebra shows that $f^{\prime}(2 b)=2(5-4 b)-\delta>$

0.

Proof of Lemma 3: (i) Note from (18) that

$$
n_{0}^{l h}=\frac{b}{2}+\frac{1}{2} \Delta\left(n_{1}^{h}\right)-\frac{1}{2} \sqrt{\left(b+\Delta\left(n_{1}^{h}\right)\right)^{2}-4 \delta}
$$

where $\Delta(n)=(1-b) n+\delta / n$. The conjectured inequality holds if

$$
\Delta\left(n_{1}^{h}\right)<\sqrt{\left(b+\Delta\left(n_{1}^{h}\right)\right)^{2}-4 \delta}
$$


Taking the square of both sides, this is equivalent to

$$
\Delta\left(n_{1}^{h}\right)^{2}<b^{2}+2 b \Delta\left(n_{1}^{h}\right)+\Delta\left(n_{1}^{h}\right)^{2}-4 \delta
$$

Simplifying,

$$
4 \delta<b^{2}+2 b \Delta\left(n_{1}^{h}\right)
$$

Since $b^{2}>4 \delta$ by assumption and $\Delta>0$, this inequality holds.

(ii) $n_{0}^{h h}>b$. From (17) the definition of $n_{0}^{h h}$, the inequality holds as long as

$$
\frac{b}{2}+\frac{1}{2} \Delta\left(n_{1}^{h}\right)+\frac{1}{2} \sqrt{\left(b+\Delta\left(n_{1}^{h}\right)\right)^{2}-4 \delta}>b
$$

Simplifying

$$
\sqrt{\left(b+\Delta\left(n_{1}^{h}\right)\right)^{2}-4 \delta}>b-\Delta\left(n_{1}^{h}\right)
$$

Squaring both sides and simplifying,

$$
b \Delta\left(n_{1}^{h}\right)>\delta
$$

From the definition of $\Delta\left(n_{1}^{h}\right)$, this becomes

$$
a n_{1}^{h}+\frac{\delta}{n_{1}^{h}}>\frac{\delta}{b}
$$

We know that $0<n_{1}^{h}<b$ which guarantees that the inequality holds.

(iii) Proof by contradiction. Assume $n_{0}^{h h} \geq 2 b$. From (17) and (18), note that $n_{0}^{h h}+n_{0}^{l h}=2 y$ where $y=\frac{1}{2}\left[b+\delta / n_{1}^{h}+a n_{1}^{h}\right]$. Then,

$$
n_{0}^{l h}=b+\frac{\delta}{n_{1}^{h}}+a n_{1}^{h}-n_{0}^{h h}
$$

We will show that $n_{0}^{h h} \geq 2 b$ implies $n_{0}^{l h}<0$. From (24), it is clear that if $n_{0}^{h h}=2 b$ implies $n_{0}^{l h}<0$, then $n_{0}^{h h}>2 b$ will also imply $n_{0}^{l h}<0$. Letting $n_{0}^{h h}=2 b$, we have

$$
n_{0}^{l h}=-b+\frac{\delta}{n_{1}^{h}}+a n_{1}^{h}
$$

Since we are interested in establishing the sign of $n_{0}^{l h}$ under the contradiction, we can multiply the above expression by $n_{1}^{h}$. Then,

$$
\operatorname{sgn}\left[n_{0}^{l h}\right]=\operatorname{sgn}\left[a\left(n_{1}^{h}\right)^{2}-b n_{1}^{h}+\delta\right]
$$


The quadratic term inside the brackets of the right-hand side of (25) is similar to the quadratic equation (14) that determines the value of $n_{1}^{h}$. In fact these two quadratic equations differ only in the coefficient multiplying the squared term. Let us define these two quadratic functions:

$$
\begin{aligned}
& F(n)=a n^{2}-b n+\delta \\
& G(n)=n^{2}-b n+\delta
\end{aligned}
$$

Figure 4 plots $F$ and $G$. First, $F$ lies below $G$ because $a<1$. Second, $G\left(n_{1}^{h}\right)=0$ since $n_{1}^{h}$ is defined by (14). Since $F$ lies beneath $G$, this implies that $F\left(n_{1}^{h}\right)<0$. From (28), however, $n_{0}^{l h}$ is negative. Examining (18), it is clear $n_{0}^{l h}$ is positive. We have reached the desired contradiction. Note that assuming $n_{0}^{h h}>2 b$ will not reverse the sign of $n_{0}^{l h}$.

Proof of Lemma 4: It is more convenient to study $V\left(n_{0}\right)=\left(n_{0}^{2}-b n_{0}+\delta\right)\left[n_{0} \exp \left(-n_{0}\right)\right]$, a monotone transformation of the utility function where we drop terms involving $n_{1}$, since they are identical across the equilibria we consider. Note,

$$
V(b)=b \delta \exp (-b)
$$

Therefore the inequality holds if

$$
\delta b \exp (-b)>\left[n_{0}^{2}-b n_{0}+\delta\right]\left(n_{0} \exp \left(-n_{0}\right)\right)
$$

The function $n_{0} \exp \left(-n_{0}\right)$ is monotonically increasing in $n_{0}$ for $n_{0}<1$. Since $b>n_{0},(26)$ must certainly hold if

$$
\delta>n_{0}^{2}-b n_{0}+\delta
$$

holds. The above inequality holds since $b>n_{0}$.

Proof of Theorem 1: From the final government's problem, $n_{1}=n_{1}^{h}$. Since the time zero government may only select from equilibrium choices of $n_{0}$ that are time consistent, the two possibilities are $n_{0}^{l h}, n_{0}^{h h}$. Combining Lemmas 2 and 4 , we know that $U\left(n_{0}, n_{1}\right)>U\left(x, n_{1}\right)$ for all $n_{0} \in[b, 2 b)$ and $x<b$. From Lemma 
3(i), $n_{0}^{l h}<b / 2$. This implies $U\left(n_{0}, n_{1}^{h}\right)>U\left(n_{0}^{l h}, n_{1}^{h}\right)$ for $n_{0} \in[b, 2 b)$. Lemmas $3(\mathrm{ii})$ and $3(\mathrm{iii})$ guarantee that $n_{0}^{h h} \in[b, 2 b)$ and the proof is complete.

Proof of Lemma 5: (i) This inequality clearly holds by inspecting (17) and (18).

(ii) This inequality clearly holds by inspecting (17) and (18).

(iii) From (17), the definition of $n_{0}^{h l}$, the inequality holds as long as

$$
\frac{b}{2}+\frac{1}{2} \Delta\left(n_{1}^{l}\right)+\frac{1}{2} \sqrt{\left(b+\Delta\left(n_{1}^{l}\right)\right)^{2}-4 \delta}>b
$$

Simplifying,

$$
\sqrt{\left(b+\Delta\left(n_{1}^{l}\right)\right)^{2}-4 \delta}>b-\Delta\left(n_{1}^{l}\right)
$$

Squaring both sides and simplifying,

$$
b \Delta\left(n_{1}^{l}\right)>\delta
$$

From the definition of $\Delta\left(n_{1}^{l}\right)$, this becomes

$$
a n_{1}^{l}+\frac{\delta}{n_{1}^{l}}>\frac{\delta}{b}
$$

We know that $0<n_{1}^{l}<b$ which guarantees that the inequality holds.

(iv) Proof by contradiction. Assume $n_{0}^{h l} \geq 2 b$. From (17) and (18), note that $n_{0}^{l l}+n_{0}^{h l}=2 y$ where $y=\frac{1}{2}\left[b+\delta / n_{1}^{l}+a n_{1}^{l}\right]$. Then,

$$
n_{0}^{l l}=b+\frac{\delta}{n_{1}^{l}}+a n_{1}^{l}-n_{0}^{h l}
$$

We will show that $n_{0}^{h l} \geq 2 b$ implies $n_{0}^{l l}<0$. From (27), it is clear that if $n_{0}^{h l}=2 b$ implies $n_{0}^{l l}<0$, then $n_{0}^{h l}>2 b$ will also imply $n_{0}^{l l}<0$. Letting $n_{0}^{h l}=2 b$, we have

$$
n_{0}^{l l}=-b+\frac{\delta}{n_{1}^{l}}+a n_{1}^{l}
$$

Since we are interested in establishing the sign of $n_{0}^{l l}$ under the contradiction, we can multiply the above expression by $n_{1}^{l}$. Then,

$$
\operatorname{sgn}\left[n_{0}^{l l}\right]=\operatorname{sgn}\left[a\left(n_{1}^{l}\right)^{2}-b n_{1}^{l}+\delta\right]
$$


The quadratic term inside the brackets of the right-hand side of (28) is similar to the quadratic equation (14) that determines the value of $n_{1}^{l}$. In fact these two quadratic equations differ only in the coefficient multiplying the squared term. Let us define these two quadratic functions:

$$
\begin{aligned}
& F(n)=a n^{2}-b n+\delta \\
& G(n)=n^{2}-b n+\delta
\end{aligned}
$$

Figure 4 plots $F$ and $G$. First, $F$ lies below $G$ because $a<1$. Second, $G\left(n_{1}^{l}\right)=0$ since $n_{1}^{l}$ is defined by (14). Since $F$ lies beneath $G$, this implies that $F\left(n_{1}^{l}\right)<0$. From (28), however, $n_{0}^{l l}$ is negative. Examining (18), it is clear $n_{0}^{l l}$ is positive. We have reached the desired contradiction. Note that assuming $n_{0}^{h l}>2 b$ will not reverse the sign of $n_{0}^{l l}$.

Proof of Theorem 2: Let $U_{0}^{i j}$ define the time zero household utility if time zero labor is $i$ and time one labor is $j$. The proof consists of three parts: (i) $U_{0}^{h h}>U_{0}^{l h}$; (ii) $U_{0}^{h l}>U_{0}^{l l}$; (iii) $U_{0}^{h l}>U_{0}^{h h}$.

(i) Lemmas 2 and 4 compare time zero utility as $n_{0}$ varies holding $n_{1}$ fixed. This makes Lemmas 2 and 4 appropriate for comparing allocations $\left(n_{0}^{h h}, n_{1}^{h}\right)$ and $\left(n_{0}^{l h}, n_{1}^{h}\right)$. Combining Lemmas 2 and 4 , we know that $U\left(n_{0}, n_{1}^{h}\right)>U\left(x, n_{1}^{h}\right)$ for all $n_{0} \in[b, 2 b)$ and $x<b$. There are two cases. First, if $n_{0}^{l h}<b$, then $U_{0}^{h h}>U_{0}^{l h}$ by Lemma 5(iii) and 5(iv) which establish that $n_{0}^{h h} \in[b, 2 b)$. Second, if $n_{0}^{l h}>b$, then $U_{0}^{h h}>U_{0}^{l h}$ by Lemma $5(\mathrm{i}), 5(\mathrm{iii})$ and $5(\mathrm{iv})$, because $U\left(n_{0}, n_{1}^{h}\right)$ is increasing in $n_{0}$ for all $n_{0} \in[b, 2 b)$.

(ii) This inequality is derived as part of the proof of Theorem 1.

(iii) $U_{0}^{h l}>U_{0}^{h h}$ is equivalent to

$$
k_{1}^{h l}\left(n_{0}^{h l} \exp \left(-n_{0}^{h l}\right)\right)\left(n_{1}^{l} \exp \left(-n_{1}^{l}\right)\right)>k_{1}^{h h}\left(n_{0}^{h h} \exp \left(-n_{0}^{h h}\right)\right)\left(n_{1}^{h} \exp \left(-n_{1}^{h}\right)\right)
$$

Let $n_{0}^{h j}=\phi^{j} /\left(2 n_{1}^{j}\right)$ for $j=l, h$. The above inequality is equivalent to

$$
\left(\frac{k_{1}^{h l} \phi^{l}}{k_{1}^{h h} \phi^{h}}\right) \exp \left(n_{1}^{h}-n_{1}^{l}\right)>\exp \left(n_{0}^{h l}-n_{0}^{h h}\right)
$$


Next, it is straightforward to show

$$
\begin{gathered}
n_{1}^{h}-n_{1}^{l}=\sqrt{b^{2}-4 \delta} \\
n_{0}^{h l}-n_{0}^{h h}=\frac{1}{2}\left[b \sqrt{b^{2}-4 \delta}+\sqrt{\left(b+\Delta\left(n_{1}^{l}\right)\right)^{2}-4 \delta}-\sqrt{\left(b+\Delta\left(n_{1}^{h}\right)\right)^{2}-4 \delta}\right]
\end{gathered}
$$

Using (30), we have an expression for the RHS of (29):

$$
\exp \left(n_{0}^{h l}-n_{0}^{h h}\right)=\exp \left(b \sqrt{b^{2}-4 \delta}\right)^{1 / 2}\left[\frac{\exp \left(\sqrt{\left(b+\Delta\left(n_{1}^{l}\right)\right)^{2}-4 \delta}\right)}{\exp \left(\sqrt{\left(b+\Delta\left(n_{1}^{h}\right)\right)^{2}-4 \delta}\right)}\right]^{1 / 2}
$$

Simplifying,

$\exp \left(n_{0}^{h l}-n_{0}^{h h}\right)=\exp \left(b \sqrt{b^{2}-4 \delta}\right)^{1 / 2}\left\{\exp \left[\left(\Delta^{l}\right)^{2}-\left(\Delta^{h}\right)^{2}+2 b\left(\Delta^{l}-\Delta^{h}\right)\right]\right\}^{1 / 4}$

This simplifies even further:

$$
\exp \left(n_{0}^{h l}-n_{0}^{h h}\right)=\exp \left(b \sqrt{b^{2}-4 \delta}\right)^{1 / 2}\left\{\exp \left[b^{2}(4-b) \sqrt{b^{2}-4 \delta}\right]\right\}^{1 / 4}
$$

The inequality (29) becomes

$$
\left(\frac{k_{1}^{h l} \phi^{l}}{k_{1}^{h h} \phi^{h}}\right) \exp \left(b^{2}-4 \delta\right)^{1 / 2}>\exp \left(b \sqrt{b^{2}-4 \delta}\right)^{1 / 2}\left\{\exp \left[b^{2}(4-b) \sqrt{b^{2}-4 \delta}\right]\right\}^{1 / 4}
$$

This completes the proof. 


\section{Bibliography}

Azariadis, Costas (1981), "Self Fulfilling Prophecies," Journal of Economic Theory $25,380-96$.

Benhabib, Jess and Roger Farmer (1994), "Indeterminacy and Increasing Returns," Journal of Economic Theory 63, 19-41.

Christiano, Lawrence and Sharon Harrison (1999), "Chaos, Sunspots and Automatic Stabilizers," Journal of Monetary Economics, forthcoming.

Cooper, Russell and Andrew John (1988), "Coordinating Coordination Failures in Keynesian Models," Quarterly Journal of Economics 103, 441-64.

Evans, George, Seppo Honkapohja and Paul Romer (1998), "Growth Cycles," American Economic Review 88, 495-515.

Farmer, Roger (1993), The Macroeconomics of Self-Fulfilling Prophecies, Cambridge, Massachusetts: MIT Press.

Farmer, Roger and Michael Woodford (1984), "Self-Fulfilling Prophecies and the Business Cycle," CARESS working paper 84-12, University of Pennsylvania.

Guo, Jang-Ting and Kevin Lansing (1998), "Sunspots and Stabilization Policy," Journal of Economic Theory 82, 481-490.

Hall, Robert (1991), Booms and Recessions in a Noisy Economy, New Haven: Yale University Press.

Howitt, Peter and R. Preston McAfee (1992), "Animal Spirits," American Economic Review 82, 493-506.

Kiyotaki, Nobuhiro (1988), "Multiple Expectational Equilibria under Monopolistic Competition," Quarterly Journal of Economics 103, 695-713. 
Kydland, Finn and Edward Prescott (1977), "Rules Rather than Discretion: The Inconsistency of Optimal Plans," Journal of Political Economy 85, 473-491.

Lucas, Robert and Nancy Stokey (1983), "Optimal Monetary and Fiscal Policy in an Economy without Capital," Journal of Monetary Economics 12, 55-93.

Matsuyama, Kiminori (1991), 'Increasing Returns, Industrialization and Indeterminacy of Equilibrium,' Quarterly Journal of Economics 106, 617-650.

Schmitt-Grohé, Stephanie (1994), "Comparing Four Models of Aggregate Fluctuations Due to Self-Fulfilling Expectations," Journal of Economic Theory 72, 96-147.

Shleifer, Andrei (1986), "Implementation Cycles," Journal of Political Economy 94, 1163-90.

Weil, Philippe (1989), "Increasing Returns and Animal Spirits," American Economic Review 79, 889-894.

Woodford, Michael (1987), "Three Questions about Sunspot Equilibria as an Explanation of Economic Fluctuations," American Economic Review Papers and Proceedings 77, 93-98.

Woodford, Michael (1988), "Expectations, Finance Constraints and Aggregate Instability," in Finance Constraints, Expectations and Macroeconomics, New York: Oxford University Press, 230-61.

Woodford, Michael (1991), "Self-Fulfilling Expectations and Fluctuations in Aggregate Demand," in New Keynesian Economics Vol. 2 (edited by N. Gregory Mankiw and David Romer), Cambridge MA: MIT Press, 77-112. 


\section{Diagram 1: Sequence of Events}

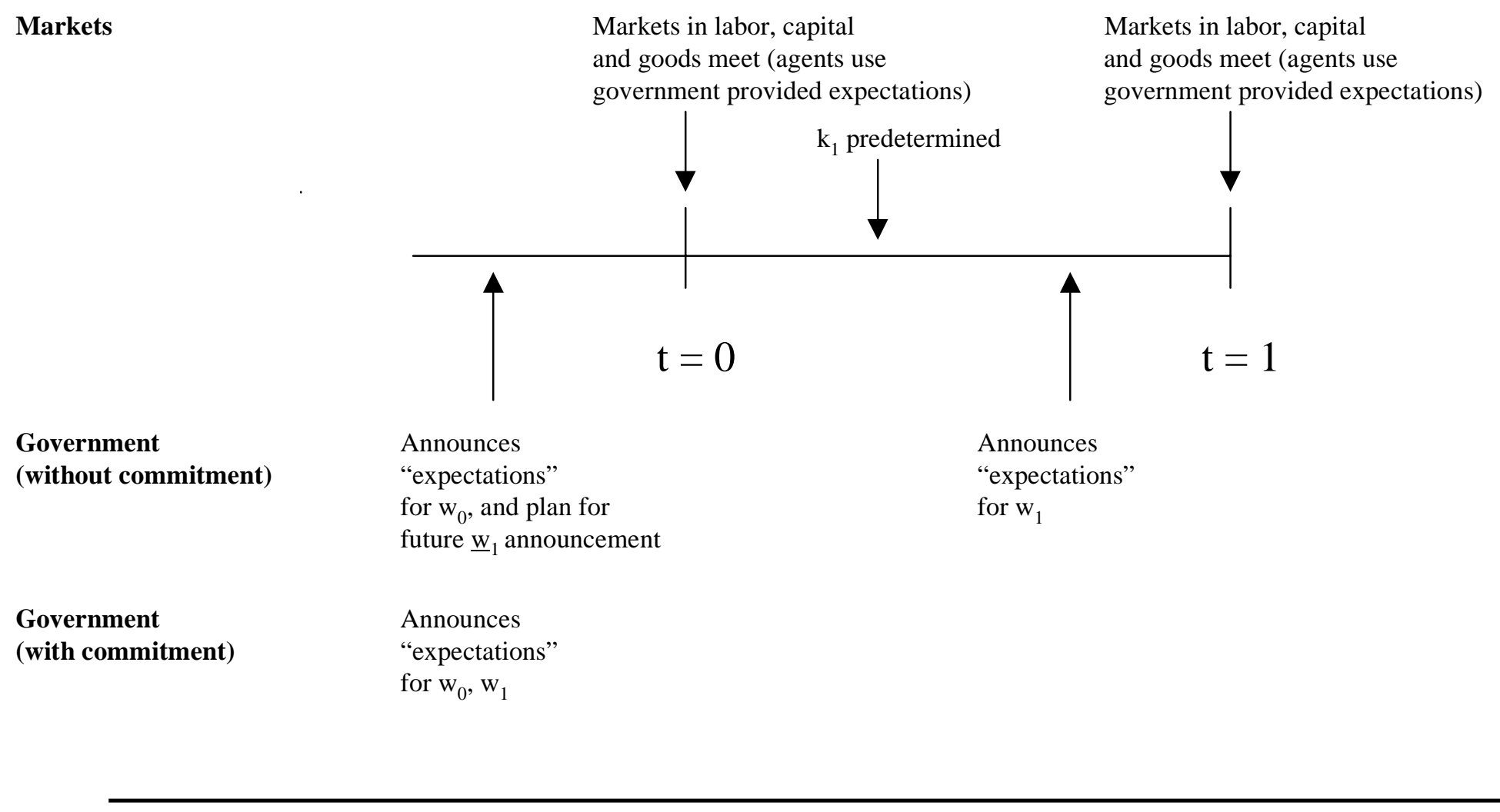

Note: At each node, government chooses policies in order to maximize future utility of households. Without commitment, time consistency requires that $\underline{\mathrm{w}}_{1}=\mathrm{w}_{1}$. 


$$
\begin{aligned}
& \text { "Keynesian Conundrum". } \\
& \text { Bill Duper } \\
& 6 / 1 / 99
\end{aligned}
$$

Figure 1

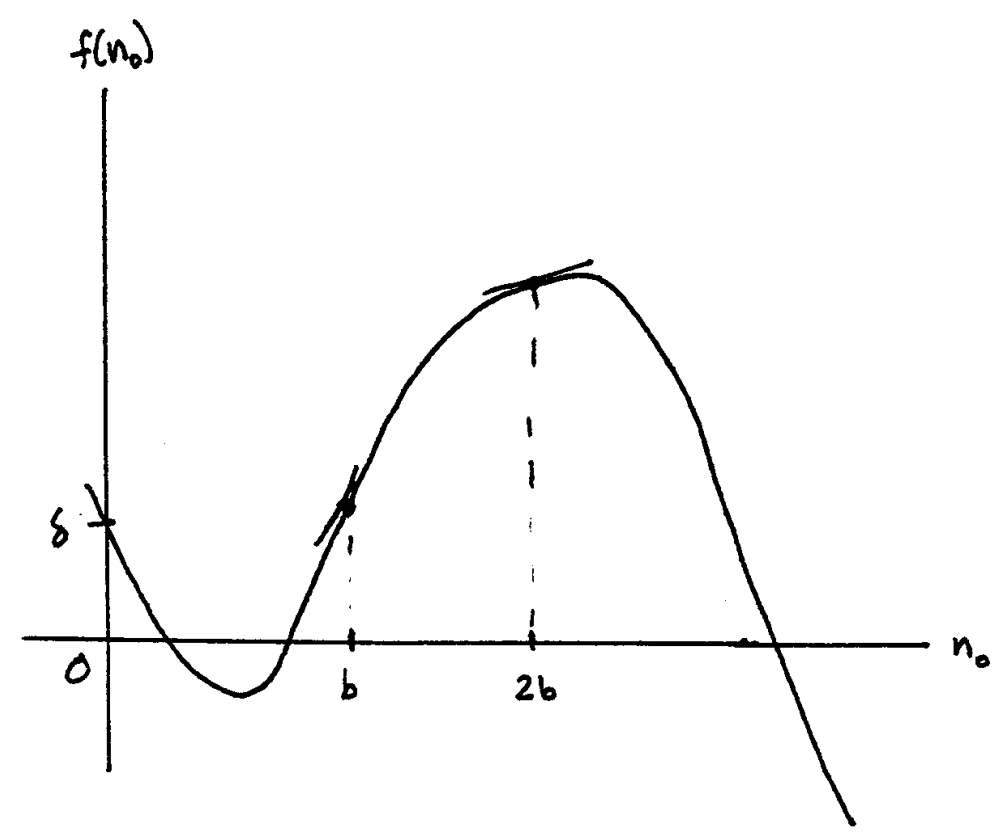

Figure 2

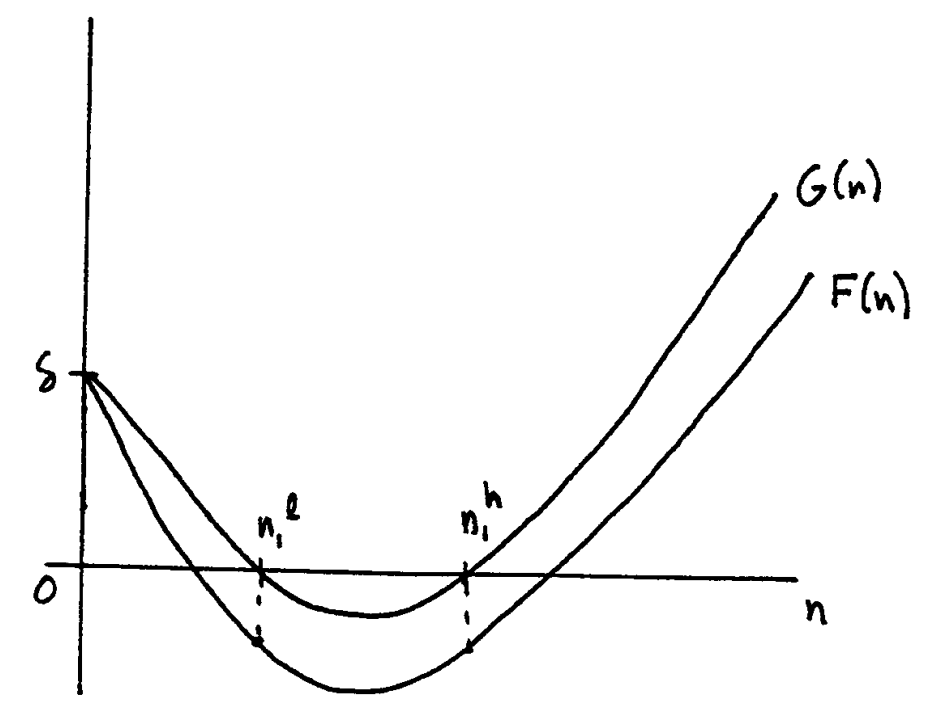




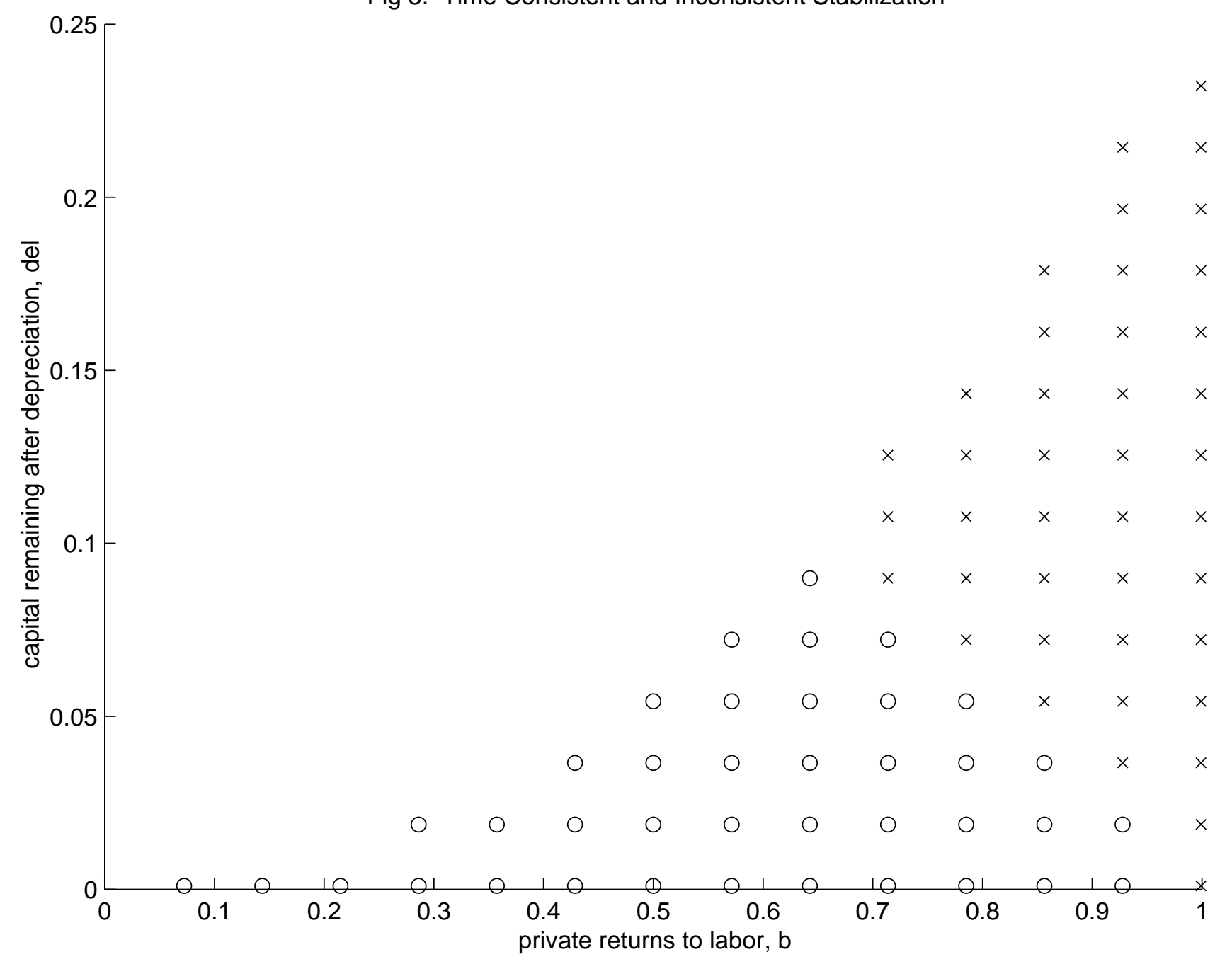




\section{Table 1: A Numerical Example}

\begin{tabular}{|l|c|c|}
\hline & Low Labor at $\mathbf{t}=\mathbf{1}$ & High Labor at $\mathbf{t}=\mathbf{1}$ \\
\hline $\begin{array}{l}\text { Low Labor } \\
\text { at } \mathbf{t}=\mathbf{0}\end{array}$ & $\mathrm{U}_{0}=-8.12$ & $\mathrm{U}_{0}=-7.52$ \\
& $\mathrm{n}_{0}=0.09 ; \mathrm{n}_{1}=0.20$ & $\mathrm{n}_{0}=0.11 ; \mathrm{n}_{1}=0.50$ \\
$\mathrm{c}_{1}=0.007 ; \mathrm{k}_{1}=0.047$ & $\mathrm{c}_{1}=0.013 ; \mathrm{k}_{1}=0.037$ \\
\hline High Labor & $\mathrm{U}_{0}=-3.96$ & \\
at t = 0 & $\mathrm{n}_{0}=1.17 ; \mathrm{n}_{1}=0.20$ & $\mathrm{U}_{0}=-4.11$ \\
& $\mathrm{c}_{1}=0.092 ; \mathrm{k}_{1}=0.658$ & $\mathrm{n}_{1}=0.94 ; \mathrm{n}_{1}=0.50$ \\
& & \\
\hline
\end{tabular}

Note: In this example, $\mathrm{b}=0.7$ and $\delta=0.1$. For every equilibrium, $\mathrm{c}_{0}=\mathrm{b}\left(\mathrm{n}_{0}\right)$. 